\title{
Biomaterials for Reconstruction of Cranial Defects
}

\section{Biomateriais para reconstrução de defeitos cranianos}

\author{
Aderaldo Costa Alves Junior ${ }^{1}$ Pedro Tadao Hamamoto Filho ${ }^{1}$ Aristides Augusto Palhares Neto ${ }^{2}$ \\ Marco Antonio Zanini ${ }^{1}$ \\ ${ }^{1}$ Department of Neurology, Psychology and Psychiatry, Faculdade de \\ Medicina de Botucatu, Universidade Estadual Paulista (FMB - UNESP), \\ Botucatu-SP, Brazil \\ 2 Department of Surgery and Orthopedics, Faculdade de Medicina de \\ Botucatu, Universidade Estadual Paulista (FMB - UNESP), Botucatu-

\begin{abstract}
Address for correspondence Aderaldo Costa Alves Junior, MD, Departamento de Neurologia, Psicologia e Psiquiatria da Faculdade de Medicina de Botucatu, Universidade Estadual Paulista (FMB - UNESP), Distrito de Rubião Jr, S/N, Botucatu, SP, Brasil, CEP: 18618-970 (e-mail: aderaldoalvesjr@gmail.com; aderaldoneuro@gmail.com).
\end{abstract} SP, Brazil

\begin{abstract}
Keywords

- cranioplasty

- biomaterials

- cranioencephalic trauma

\section{Resumo}

\section{Palavras-chave}

- cranioplastia

- biomateriais

- traumatismo cranioencefálico

Cranioplasty is defined as the surgical repair of a cranial defect to restore the structure and function of the skull. Archaeological records show attempts of cranioplasty since the dawn of human civilization, but until today there is no consensus among neurosurgeons around the world-regarding the best material for cranioplasty. Relocation of the originally removed bone graft is still the best option, but is not always available. In modern cranioplasty, different materials can be used for the repair of cranial defects, such as metals, plastics, acrylics, and ceramics. Recent studies have sought to identify which materials provide the best long-term results, but scientific evidence is poor. Presurgical decisions must consider the experience of the surgical service and the individual conditions of the patient. In this study, we discuss the main characteristics of the materials used today for the reconstruction of cranial defects.

A cranioplastia é definida como o reparo cirúrgico de um defeito craniano, com o objetivo de restaurar a estrutura e a função do crânio. Evidências arqueológicas demonstram tentativas de cranioplastia desde os primórdios da civilização humana, porém ainda hoje não há consenso entre neurocirurgiões de todo o mundo a respeito do melhor material para a cranioplastia. Realocar o enxerto ósseo originalmente removido ainda é a melhor opção, porém nem sempre é uma possibilidade. Na cranioplastia moderna, diferentes materiais podem ser utilizados para reparar o defeito craniano, tais como metais, plásticos, acrílicos e cerâmicas. Estudos recentes vêm buscando identificar quais os materiais com melhores resultados em longo prazo; entretanto, as evidências científicas são escassas. Decisões pré-cirúrgicas devem levar em consideração a experiência do serviço cirúrgico e as condições individuais do paciente. Neste estudo discutimos as principais características dos materiais utilizados para o reparo de defeitos cranianos na atualidade.
\end{abstract}

received

July 16, 2016

accepted

August 30, 2016

published online

October 25, 2016
DOI http://dx.doi.org/

10.1055/s-0036-1592411. ISSN 0103-5355.
Copyright $\odot 2016$ by Thieme-Revinter

Publicações Ltda, Rio de Janeiro, Brazil
License terms

(요 (1) $\circledast$ 


\section{Introduction}

Decompressive craniectomy is routinely used in neurosurgery for the treatment of traumatic brain injury and of complications of cerebrovascular diseases associated with increased intracranial pressure, such as malignant middle cerebral artery infarction and spontaneous subarachnoid hemorrhage. The efficacy of this procedure in reducing intracranial pressure by removing a bone flap associated with duraplasty has been established in the literature over the last decades. However, the cranial defect resulting from the surgical procedure poses a challenge in terms of the best technique and materials for reconstruction on a second occasion. ${ }^{1}$

Cranioplasty is defined as the surgical repair of a cranial defect. Its objective is to restore the structure and function of the skull, promoting brain protection and optimizing cerebral hydrodynamic conditions and esthetics. ${ }^{2-4}$ The syndrome of the trephined, first described in 1939, consists of behavioral changes and symptoms in craniectomized patients as a result of non-physiological brain conditions under the direct effect of atmospheric pressure and without appropriate cranial protection. The restoration of homeostatic brain patterns after cranioplasty leads to a decrease in these symptoms, improves neurological performance and reduces the incidence of epilepsy as a result of changes in cerebrospinal fluid (CSF) flow, cerebral perfusion and metabolism, which have been well documented in cerebral perfusion imaging studies and neuropsychological tests. ${ }^{5-7}$ A recent thesis studying the effects of cranioplasty demonstrated the improvement of symptoms associated with craniotomy, as well as an increase in intracranial arterial blood flow velocity measured by transcranial Doppler after cranial reconstruction. ${ }^{8}$

Archaeological records show attempts of cranioplasty since the dawn of human civilization. ${ }^{3}$ However, the modern technique of cranioplasty, as used today, has been performed only since the second half of the last century, and there is still no consensus among neurosurgeons around the world regarding the best material for this procedure. ${ }^{4}$ An estimated 30 thousand surgical reconstruction procedures of craniofacial bone defects are performed annually in the United States alone. ${ }^{9}$ This growing demand has made cranioplasty an object of study of public interest.

\section{History}

Cranioplasty has been performed by many ancient civilizations, including the Incas, British, Asian, North African and Polynesian populations, with records dating back to 7,000 BC. However, the first description in the medical literature only appears in the 16th century, when Fallopius and Petronius published their work on cranial defect reconstruction using gold plates.,10 At that time, the idea of using a prosthesis for the surgical procedure was not well accepted, and surgeons preferred to relocate any viable bone fragments connected to adjacent tissues after head trauma. However, this technique was not always applicable, and most patients remained with a cranial defect. In subsequent centuries, new attempts to repair cranial defects arose. In the 18th and 19th centuries, there was a tendency to use bone grafts. Autografts were avoided not only because of the fear of cranial complications, but also of complications at the donor site. Thus, despite the high immune response, allografts with cadaveric skulls or heterografts were preferred, and canine, bovine and rabbit bones were tested. ${ }^{11}$ Finally, in the last century, during the World Wars, the use of non-biological prostheses became more common, and these prostheses evolved. In World War I, there was a preference for the metals gold and silver, while titanium started to be used in World War II. Since the 1940's, with the discovery of the surgical use of acrylic, non-metal prostheses gained relevance. ${ }^{10}$

\section{Materials for Cranioplasty}

The search for the best material for cranioplasty continues. Relocation of the originally removed bone graft is still the best option; however, its unavailability in most cases, and the difficulties in preserving the removed bone are important obstacles. Bone grafts, human or not, have been tested throughout the history of surgery for cranial defect repair, and continue to be used today. However, some issues limit their use, such as the challenge of preventing bone resorption, immune reactions, and contamination risks. Researchers have therefore tried to develop prostheses that can replace bone, but their complication rates are still high in clinical practice. ${ }^{12}$ The average infection rate following cranioplasty is $10 \%$. This rate varies depending on the type of material used; polymethylmethacrylate (PMMA) implants cause infection in 5.8 to $18.4 \%$ of cases, while the infection rate associated with titanium implants ranges from 2.6 to $18.4 \%$. Studies using polyetheretherketone (PEEK) report infection rates of 8.3 to $22 \%$, while the lowest percentage was observed for hydroxyapatite, $2.05 \%$. However, these are more recent materials, and further studies are needed. ${ }^{2}$

The ideal alloplastic material should have physical properties similar to those of the bone, including biocompatibility, adequate mechanical strength, and low heat conductivity. Furthermore, the material should be resistant to infections, malleable to properly fit defects with complete closure, and readily available for use at reasonable costs. ${ }^{3,4}$

\section{Autograft}

The first recorded cranioplasty using autologous bone is credited to the surgeon Walther, and it was performed in 1821. ${ }^{3}$ Autografts are preferred, since the introduction of foreign material in the body is avoided, and because of their low cost. The property of osteoconduction, that is, the ability to induce bone growth, allows the bone graft, once it is accepted by the recipient site, to be reintegrated into the skull. However, this mechanism requires good blood supply and adequate fixation to the adjacent bone to permit osteoblast migration. Thus, the quality of the recipient site tissue and the stability of contact between the graft and the skull are crucial, and may compromise the results of larger cranial defects treated by this method, in which high rates of bone 
resorption are observed. Additionally, the graft must have a matrix that promotes osteoblast allocation. An incidence of bone resorption of $2-32 \%$ has been reported in adults, and $50-66 \%$ in children. ${ }^{2-4}$

Diverse donor sites are used for autografting. The use of the tibia has been reported since 1889, when Seydel extracted parts of this bone and successfully covered a left parietal defect. ${ }^{3}$ Ribs, in whole or in part, may also be used, but several studies have reported high rates of resorption. There are also reports of the use of the hip bone. However, all of these techniques require a second surgical site, thus increasing the patients' discomfort, with high rates of resorption regardless of the donor site. Autografts can be extracted more easily from the skull itself, with better outcomes., ${ }^{3,4}$ This technique is known as "split-skull cranioplasty" in which a craniotomy is performed contralateral to the defect in a mirror model. The outer and inner tables of the cranial bone are then separated, which results in two grafts that serve as donor and recipient respectively. ${ }^{13}$

There is also the possibility of relocating the bone flap removed during decompressive craniotomy, a commonly used surgical practice. In this case, the bone graft is stored in the abdominal subcutaneous tissue or preserved by freezing it at a temperature of -16 to $-80^{\circ} \mathrm{C}$. Clinical studies have found no statistically significant differences in infection rates after cranioplasty between the two techniques; however, a possible and frequent complication is the resorption of the bone graft. ${ }^{14}$ The matrix of the bone flap may be destroyed during sterilization by autoclaving after extracorporeal preservation, a fact that would explain the high rate of resorption associated with the method. ${ }^{3}$ In neurosurgical practice, abdominal preservation is preferred because of its convenience and low cost despite the additional risk of bone resorption during the period of storage.

\section{Allograft and Xenograft}

Graft bone harvested from cadavers, known as allograft, has been commonly used in clinical practice in the past. However, allografts have become uncommon in cranial reconstruction because of factors such as high resorption rates, unwanted immune responses, and the historical resistance against the use of this method. ${ }^{4}$

For centuries, bone grafts obtained from species other than humans (xenografts) have been used for the reconstruction of cranial defects. The use of canine bone was reported by van Meekeren in 1668; Schmidt reported the use of rabbit bone in 1893, and the use of bovine bone was reported by Grekopf in 1898 and by Babcock in 1917. In 1901, Marchand published a study on the use of animal horns, which showed good tolerability. Bones of other animals have been tested, including monkeys, geese and eagles. ${ }^{3,11}$ The development of new techniques and materials made allografts and xenografts uncommon in contemporary cranioplasty.

\section{Metals}

The first metal with historical records to be used as material for cranial defect correction was gold. In this respect, there is archaeological evidence of a Peruvian skull dating back to
2,000 BC with a left frontal defect covered with a 1-mm thick gold plate. ${ }^{3}$ This metal has also been used after the Middle Ages until the beginning of the last century, but its high cost and softness led to its disuse. Silver, which is less expensive than gold, had its use popularized after a report by Sebileau in $1903 .^{3}$ However, in medical practice, silver proved to be too malleable to confer adequate protection, and could also induce an oxidation reaction after its interaction with the surrounding tissue, leading to discoloration of the scalp. Aluminum was also tested in the 19th century, but adverse effects such as seizures caused by irritation of the brain and material degradation have discouraged its use. . $^{3,10,11}$

\section{Titanium}

The use of titanium for cranioplasty started in World War II, but the technique has been improved after the 1980s, with the appearance of complex designs, such as meshes, which provide greater flexibility and endurance. This metal is noncorrosive and highly biocompatible, with a virtually nonexistent risk of allergic reactions. Furthermore, it is associated with low rates of infection. These features have made titanium the most widely used material today (-Fig. 1). The main disadvantage of titanium is its high cost. Recently, 3D prosthetic models, custom-made by computers based on tomographic images, have optimized esthetic results, even in the case of larger defects. ${ }^{4}$

\section{Acrylic}

Acrylic resins gained surgical interest due to their successful application to the modeling of dental prostheses. Polymethylmethacrylate (PMMA) is a polymerized ester of acrylic acid discovered in the 20th century, and it was used for the first time in surgical practice by Zander in $1940 .^{10}$ This material has strength and biocompatibility comparable to those of the bone, and adheres to the dura mater without reacting with soft tissues. Its advantages over metals include greater flexibility, lower heat conductivity, decreased

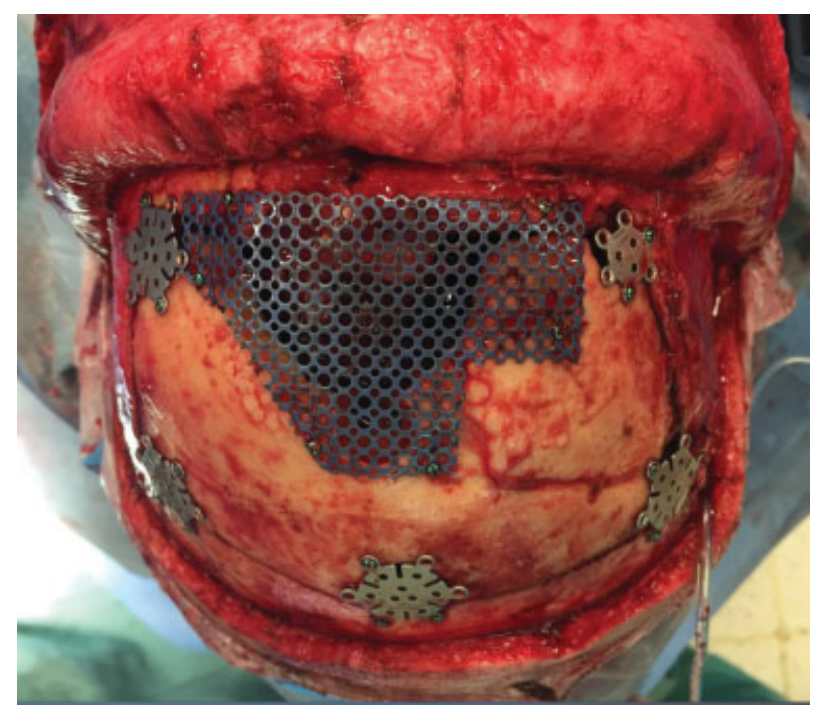

Fig. 1 Intraoperative aspect of cranioplasty with a titanium mesh to cover a frontal defect. 


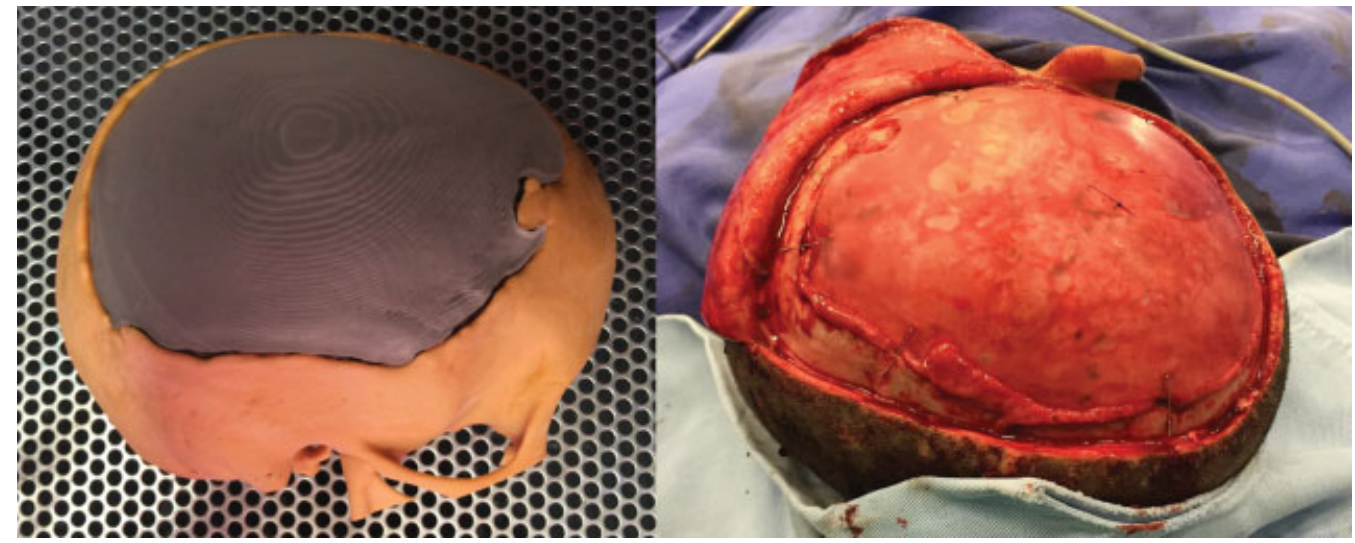

Fig. 2 Cranioplasty with a custom-made PMMA prostheses based on tomographic 3D images. Cranial model and the prosthesis before sterilization process (left); Intraoperative aspect after fixation to the skull (right).

density and lower cost, as well as its radiolucent property, allowing the visualization of underlying tissues at imaging. Moreover, recent technological advances led to the the development of custom-made prostheses based on 3D computed tomographic images, with excellent esthetic results ${ }^{15}$ (-Fig. 2). Polymethylmethacrylate is one of the most used materials for reconstruction of cranial defects, but its main disadvantages are the risk of decomposition, infections and rupture of the material. For this reason, in neurosurgical practice, titanium plates are used in combination to provide support for the acrylic, increasing its mechanical strength and allowing better modeling of the prosthesis ${ }^{3,4,10}$ (-Fig. 3).

\section{Ceramics}

The ceramic materials used in cranioplasty are crystalline compounds that have a structure similar to that of the bone, allowing for better osteoconduction. The most common ceramics are hydroxyapatite and carbonated calcium phosphate cement. The former is a type of calcium phosphate present as the mineral component in bone and teeth. In 1951, Ray and Ward tested the use of granular hydroxyapatite to repair cranial defects in animals. This compound is still used today, particularly in conjunction with titanium plates to

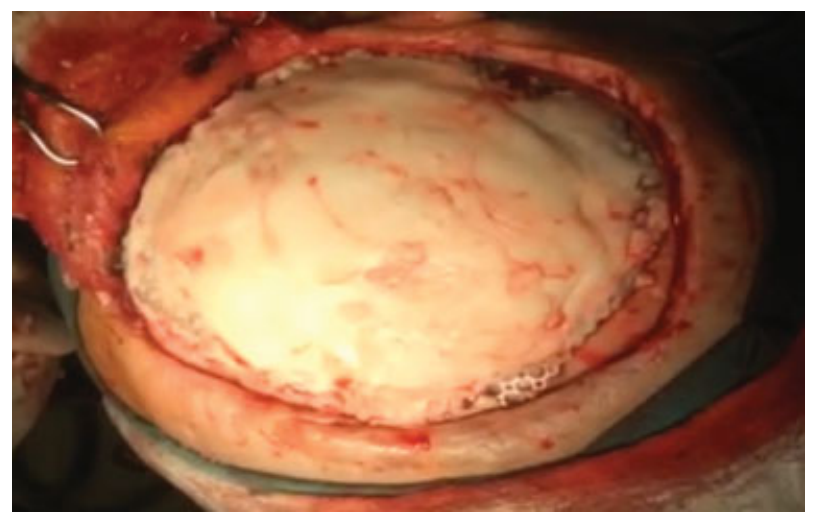

Fig. 3 Cranioplasty of a large cranial defect using PMMA prosthesis combined with a titanium mesh to confer bigger resistance. increase the strength of prostheses. The calcium phosphate cement has also been used, but is associated with problems such as fast resorption and low mechanical stability. For this reason, the application of ceramics is restricted to small defects. ${ }^{3,4}$

\section{Plastics}

The first synthetic plastic used in cranial reconstruction was celluloid in the late 19 th century. ${ }^{10}$ However, due to limitations related to the fact that this material elicits an intense inflammatory tissue response that leads to the formation of an exudate requiring reoperation, its use was restricted, and celluloid lost space to acrylic resins after their emergence in the 20th century. Nevertheless, plastic materials are still used in cranioplasty. Currently, the main representatives of this group are PEEKand polyethylene, which are durable, inert and non-degradable. Polyetheretherketone is a semicrystalline polymer and was initially developed for use in spinal surgery and for the production of hip prostheses in $1998 .^{10}$ The use of PEEK as prosthesis for cranial defects has gained acceptance because it shows resistance comparable to that of the cortical bone, and is less dense and less conductive than other materials. Recently, technology has been developed based on computed tomographic images for the fabrication of custom-made 3D prostheses, optimizing the esthetic result. Despite these advantages, the material is expensive, and does not exhibit osteoconductive properties. Moreover, since it is a recent material, additional years of practical experience are necessary to demonstrate its longterm results in cranial defect reconstruction. ${ }^{3,4,10}$

\section{Evidence for the use of Biomaterials}

Several studies comparing different types of biomaterials for cranioplasty are available in the medical literature. However, the technical variability among surgeons impairs the standardization of scientific trials and makes it difficult to obtain reliable statistical evidence. Consequently, most studies report the experiences of surgical services with the protocols being highly influenced by observational data and personal 
Table 1 Comparison of the main characteristics of the biomaterials currently used in cranioplasty ${ }^{18}$

\begin{tabular}{|l|l|l|l|l|l|l|}
\hline Material & Cost & Osteoconduction & Infection rates & Resistance & Radiolucent & Disadvantages \\
\hline Autograft & low & high & moderate & high & no & bone resorption \\
\hline Titanium & high & low & moderate & high & no & $\begin{array}{l}\text { high cost, thermal } \\
\text { conduction }\end{array}$ \\
\hline Acrylics & moderate & low & high & low & yes & fracture, infection \\
\hline Hydroxyapatite & moderate & high & moderate & low & no & resorption, low resistance \\
\hline PEEK & high & low & low & high & yes & high cost \\
\hline
\end{tabular}

Abbreviation: PEEK, polyetheretherketone.

preferences, a fact that impairs the comparison between results. $^{14}$

There is consensus among surgeons regarding the preference for autografts compared with alloplastic materials because of the theoretically reduced risk of rejection and immune responses, in addition to the fact that they provide a substrate for bone growth and revascularization. However, a systematic review ${ }^{14}$ found no scientific evidence of differences in infection rates between the two types of grafts. The same is observed when abdominal subcutaneous or extracorporeal preservation of the bone flap is compared, with no statistically significant differences in infection rates.

Recent studies have compared the different types of alloplastic materials. In the case of PEEK versus titanium, poor statistical evidence justifies the choice of one material over the other, with the use of titanium being more acceptable in clinical practice due to its lower cost. ${ }^{16}$ Titanium has also been compared with hydroxyapatite, with the observation of lower rates of infection for the ceramic compound, but, once more, the difference was not significant.-Table 1 summarizes the main characteristics of the materials used for the correction of cranial defects.

\section{Conclusions}

Cranioplasty has been performed for centuries. Nevertheless, the postoperative complication rate continues to be high, with elevated rates of reoperation, infection and resorption of the implanted graft. Recent studies have sought to identify which materials provide the best long-term results, but scientific evidence is poor. There is currently no consensus regarding the ideal material to be used in cranioplasty, and presurgical decisions must consider the experience of surgical service and the individual conditions of the patient. ${ }^{2,17}$

\section{References}

1 Honeybul S, Ho KM. Long-term complications of decompressive craniectomy for head injury. J Neurotrauma 2011;28(6):929-935

2 Servadei F, Iaccarino C. The therapeutic cranioplasty still needs an ideal material and surgical timing. World Neurosurg 2015;83(2): 133-135
3 Shah AM, Jung H, Skirboll S. Materials used in cranioplasty: a history and analysis. Neurosurg Focus 2014;36(4):E19

4 Goldstein JA, Paliga JT, Bartlett SP. Cranioplasty: indications and advances. CurrOpinOtolaryngol Head Neck Surg 2013;21(4): 400-409

5 Paredes I, Castaño AM, Cepeda S, et al. The Effect of Cranioplasty on Cerebral Hemodynamics as Measured by Perfusion Computed Tomography and Doppler Ultrasonography. J Neurotrauma 2016; 33(17):1586-1597

6 Aydin S, Kucukyuruk B, Abuzayed B, Aydin S, Sanus GZ. Cranioplasty: Review of materials and techniques. J Neurosci Rural Pract 2011;2(2):162-167

7 Honeybul S, Janzen C, Kruger K, Ho KM. The Incidence of Neurologic Susceptibility to a Skull Defect. World Neurosurg 2016; 86:147-152

8 Oliveira AMP. Efeitos da cranioplastia em doentes submetidos à craniectomia descompressiva: avaliação anatômica, neurológica e da hemodinâmica encefálica [Thesis]. São Paulo: Faculdade de Medicina da Universidade de São Paulo; 2015.

9 Kim J, McBride S, Fulmer M, et al. Fiber-reinforced calcium phosphate cement formulations for cranioplasty applications: a 52-week duration preclinical rabbit calvaria study. J Biomed Mater Res B ApplBiomater 2012;100(4):1170-1178

10 Harris DA, Fong AJ, Buchanan EP, Monson L, Khechoyan D, Lam S. History of synthetic materials in alloplastic cranioplasty. Neurosurg Focus 2014;36(4):E20

11 P. Santoni- Rugiu. P.J. Sykes. A history of Plastic Surgery. SpringerVerlag, Berlin, 2007

12 Arnaud E. Advances in cranioplasty with osteoinductive biomaterials: summary of experimental studies and clinical prospects. Childs NervSyst 2000;16(10-11):659-668

13 Zins JE, Langevin CJ, Nasir S. Controversies in skull reconstruction. J CraniofacSurg 2010;21(6):1755-1760

14 Yadla S, Campbell PG, Chitale R, Maltenfort MG, Jabbour P, Sharan AD. Effect of early surgery, material, and method of flap preservation on cranioplasty infections: a systematic review. Neurosurgery 2011;68(4):1124-1129, discussion 1130

15 Lajarin SF. Avaliação dimensional de implantes sob medida para cranioplastia [Dissertation]. Curtiba: Universidade Federal do Paraná; 2008

16 Thien A, King NKK, Ang BT, Wang E, Ng I. Comparison of polyetheretherketone and titanium cranioplasty after decompressive craniectomy. World Neurosurg 2015;83(2):176-180

17 Lindner D, Schlothofer-Schumann K, Kern BC, Marx O, Müns A, Meixensberger J. Cranioplasty using custom-made hydroxyapatite versus titanium: a randomized clinical trial. J Neurosurg 2016;26:1-9

18 Song T, Qiu ZY, Cui FZ. Biomaterials for reconstruction of cranial defects. Front Mater Sci 2015;9(4):346-354 